Gynecologic and

Obstetric Investigation
Gynecol Obstet Invest 2014;78:230-234

DOI: $10.1159 / 000363748$
Received: January 14, 2014

Accepted after revision: May 18, 2014

Published online: July 16, 2014

\title{
Vaginal Misoprostol versus a Rectal Nonsteroidal Anti-Inflammatory Drug to Reduce Pain during Pipelle Endometrial Biopsies: A Prospective, Randomized, Placebo-Controlled Trial
}

\author{
Elcin Telli Yunus Aydin Tufan Oge Omer Tarik Yalcin
}

Department of Obstetrics and Gynecology, Eskisehir Osmangazi University School of Medicine, Eskisehir, Turkey

\section{Key Words}

Misoprostol · Nonsteroidal anti-inflammatory drug ·

Pipelle biopsy · Visual analog scale

\begin{abstract}
Background: To evaluate and compare the efficacy of vaginal misoprostol and a rectal nonsteroidal anti-inflammatory drug (NSAID) on pain relief during Pipelle endometrial biopsies in a placebo-controlled randomized study. Methods: One hundred and fifty-one women who had an indication for a Pipelle endometrial biopsy were randomized into three groups as follows: group 1, vaginal misoprostol; group 2, rectal NSAID, and group 3, control. After the procedure, the women were asked to record their pain severity on a visual analog scale. The secondary outcome of the study was patient acceptability, and vasovagal symptoms and analgesic requirements after the procedure were also recorded. Results: There were no statistically significant differences in the demographic characteristics of the patients. The primary study outcome was the comparison of the median visual analog scale pain scores of groups 1 and 2 versus group 3 (controls); no statistically significant differences were found ( $p=0.502$ ). In addition, the patient acceptability (Likert scale), vasovagal symptoms and analgesic requirements after the procedure were similar among the groups ( $p=0.204,1$ and 0.546 , respectively). Conclusion: Our study did not demonstrate a reduction in pain
\end{abstract}

\section{KARGER}

E-Mail karger@karger.com

www.karger.com/goi relief during Pipelle endometrial biopsies for patients receiving vaginal misoprostol or a rectal NSAID when compared to patients receiving placebo treatment. @ $2014 \mathrm{~S}$. Karger AG, Basel

\section{Introduction}

Endometrial biopsy is a common outpatient procedure that is used to investigate endometrial pathologies that cause irregular menstrual bleeding and postmenopausal bleeding, as well as for hormone therapy monitoring $[1,2]$. Pipelle endometrial biopsy is one of the procedures used to evaluate the endometrium. Compared with classical dilation and curettage, the Pipelle biopsy was reported to have acceptable diagnostic accuracy for endometrial lesions, with the exception of focal lesions $[3,4]$. Although the Pipelle procedure is more comfortable than dilation and curettage, patients may still suffer from discomfort and pain. Several pain-reduction methods have been evaluated in the literature; for example, intrauterine anesthesia, intrauterine anesthesia plus a nonsteroidal anti-inflammatory drug (NSAID), topical analgesia, intrauterine anesthesia plus buccal misoprostol, and transcutaneous electrical nerve stimulation have been tested [5-11]. The local benzocaine study was the only study that did not demonstrate pain reduction [7]. 
Misoprostol is a synthetic E1 prostaglandin analog that is primarily used for gastrointestinal ulcers and cervical ripening. The cervical ripening effect of misoprostol by different routes of administration has been demonstrated in labor, abortion induction and hysteroscopy [12-14]. Only a few studies have evaluated the use of misoprostol administered via different routes for women undergoing dilation and curettage. Most of these studies reported no benefits of misoprostol usage either for cervical ripening or pain reduction [15-18]. However, to the best of our knowledge, there are no studies evaluating the pain reduction effect of vaginal misoprostol during Pipelle endometrial biopsies.

NSAIDs have been used for pain relief in several gynecology procedures, such as episiotomies, pregnancy terminations, and dilation and curettage, as well as in gynecological clinical conditions, such as dysmenorrhea [1921]. Although data are available regarding the use of NSAIDs in routine gynecology procedures, the effect of rectal NSAIDs for pain relief in Pipelle endometrial biopsies has not been evaluated. Therefore, the aim of this study was to evaluate and compare the effects of vaginal misoprostol and a rectal NSAID for pain relief during Pipelle endometrial biopsies.

\section{Materials and Methods}

This prospective, randomized controlled trial was designed to evaluate the efficacy of vaginal misoprostol and rectal NSAIDs on pain relief during Pipelle endometrial biopsies. The study was conducted in the Department of Gynecology and Obstetrics at a university hospital between June 2012 and August 2013. The study was approved by the ethics committee of the university and a patient consent form was obtained from all patients.

Women who had an indication for a Pipelle endometrial biopsy were invited to participate in the study. The inclusion criterion was patients with an indication for a Pipelle endometrial biopsy. The exclusion criteria for the enrollment were the following: (1) contraindications for misoprostol, such as an allergy to prostaglandins or recommendations by the manufacturer; (2) contraindications for NSAIDs, such as renal or cardiac failure, gastric or duodenal ulcers, or previously determined adverse effects; (3) contraindications to endometrial biopsy, such as cervical stenosis, active cervicitis, endometritis or pregnancy; (4) a recent history of labor or abortion; (5) hematological diseases, such as a coagulation defect or thrombocytopenia; (6) current use of analgesics or anticoagulants, and (7) a previous cervical operation.

Patients were informed of their eligibility and invited by members of the research team to join the study. A consent form was signed by the patients, and they were assigned to one of three groups using computer-based randomization: group 1, vaginal misoprostol; group 2, rectal NSAID, or group 3, control. Only a healthcare provider had the information about the enrollment and group numbers that were identified by the computer program, and this information was kept in an envelope. The only surgeon (E.T.) who performed the endometrial biopsy was blinded to group allocation, as were the patients enrolled in the study. The patients were asked to administer the drugs themselves at the appropriate time.

The women in group 1 self-administered $200 \mu \mathrm{g}$ of misoprostol (Cytotec $^{\circledR}$, ARIS, Istanbul, Turkey) vaginally $6 \mathrm{~h}$ before the biopsy, and rectal placebo tablets $30 \mathrm{~min}$ before the endometrial biopsy. The women in group 2 self-administered $100 \mathrm{mg}$ of rectal indomethacin (Endol ${ }^{\circledR}$, DEVA, Istanbul, Turkey) $30 \mathrm{~min}$ before the biopsy, and vaginal placebo tablets $6 \mathrm{~h}$ before the biopsy. The women in group 3 self-administered vaginal placebo tablets $6 \mathrm{~h}$ before their biopsy, and rectal placebo tablets $30 \mathrm{~min}$ before the biopsy. The vaginal and rectal placebo tablets were similar in appearance to misoprostol and indomethacin, respectively.

Patients underwent a standard pelvic examination, and a speculum was inserted into the vagina to visualize the cervix. The cervix and vagina were washed with an antiseptic solution. A Pipelle was passed through the cervix and a tenaculum was used if force was required to enter the cervical canal. The Pipelle device was passed into the uterus four times to sample each wall, and the specimen was placed into a formalin-filled box for pathological examination. The pathological results of the patients were also recorded.

Immediately after the procedure, the patients were asked to record their pain severity on a 10-point visual analog scale ranging from 0 (no pain) to 10 (unbearable pain). The secondary outcome of the study, patient acceptability, was recorded by the surgeon on a 5-point Likert scale. The patients were observed for $30 \mathrm{~min}$ to record any side effects related to the procedure, such as vomiting, sweating, syncope, hypotension and bradycardia. The postprocedure analgesic requirements were also recorded.

The sample size was estimated according to the study performed by Dogan et al. [7]. We assumed that the maximum mean difference among the groups was 1.3 and the standard deviation for each group was 2 . We applied a power analysis for a one-way ANOVA and estimated that 47 patients in each group would be sufficient to achieve $80 \%$ power with a type I error of 0.05 . We predicted that none of the participants would be lost during the follow-up, but we determined that we would not be able to complete the procedure for all patients due to technical difficulties; therefore, we added $10-15 \%$ more patients, and a sample size of 55 participants was selected for each group.

The statistical analysis was performed using IBM Statistics 20.0 and Minitab 16.0. The normality of continuous variables was evaluated by the Shapiro-Wilk test. The Kruskal-Wallis test was used for nonnormally distributed variables, and the results were expressed as the median with 25 th to 75 th percentiles. The $\chi^{2}$ test with frequencies and percentiles was used for categorical variables. A $p$ value $<0.05$ was considered to be statistically significant.

\section{Results}

During the study period, 165 women with an indication for an endometrial biopsy were interested in joining the study. After excluding 14 women (3 with cervical stenosis, 2 with hypersensitivity to misoprostol, 3 with hypersensitivity to NSAIDs, 2 with active cervical infections, 
Fig. 1. Patient flowchart.

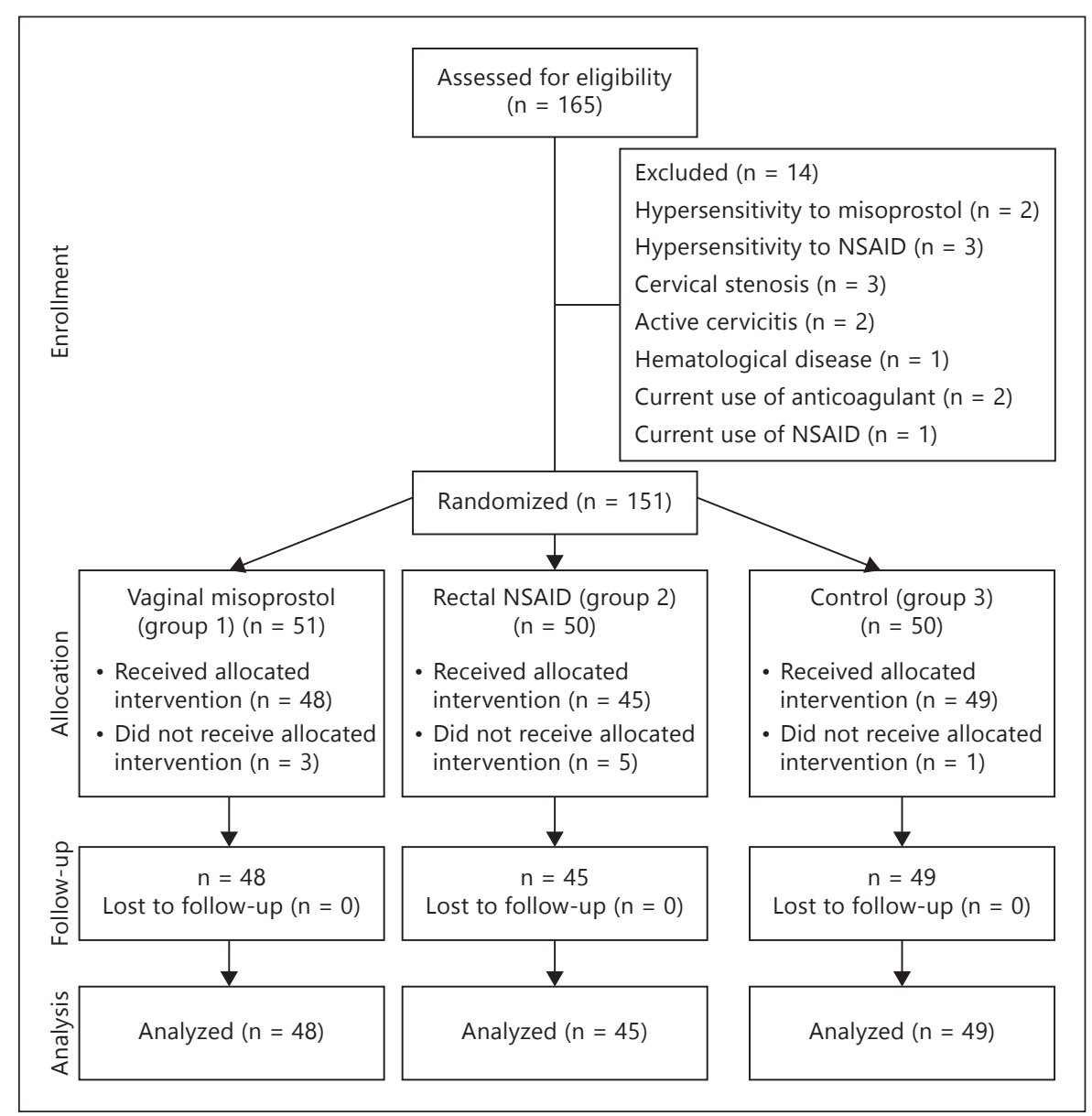

1 with a hematological disease, 2 who were on anticoagulant therapy and 1 who was currently using NSAIDs), 151 women were randomly allocated to group $1(\mathrm{n}=51)$, group $2(n=50)$ or group $3(n=50)$. Nine patients did not receive the allocated intervention; therefore, data for 142 patients were available for analysis (fig. 1).

The indications for a Pipelle endometrial biopsy were irregular menstrual bleeding ( $\mathrm{n}=71,50 \%)$, postmenopausal bleeding $(\mathrm{n}=59,42 \%)$ and evaluation of endometrial hyperplasia after treatment $(n=12,8 \%)$. There were no statistically significant differences in the following demographic characteristics: age, body mass index (BMI), gravida, parity and the number of previous vaginal deliveries (table 1). There were also no statistically significant differences in menopausal status or the number of nulligravida patients ( $\mathrm{p}=0.25$ and 0.71 , respectively). The proportion of patients with vaginal delivery was $91.6 \%$ $(\mathrm{n}=44), 86.6 \%(\mathrm{n}=39)$ and $87.7 \%(\mathrm{n}=43)$ in groups 1 , 2 and 3 , respectively. The differences in the indications for endometrial biopsy were not statistically significant among the groups $(\mathrm{p}=0.159)$. The use of a tenaculum was also similar between the groups $(n=9,19 \% ; n=8,18 \%$; $\mathrm{n}=7,14 \%$, in groups 1,2 and 3 , respectively; $\mathrm{p}=0.447$ ). The primary study outcome, the median visual analog scale pain score, was not significantly different between groups 1 and 2 in comparison to the control group (group $3 ; p=0.502$ ). There were no statistically significant differences in the patient acceptability (Likert scale), vasovagal symptoms and analgesic requirements after the procedure ( $\mathrm{p}=0.204,1,0.546$, respectively; table 1$)$. According to the histopathological results, there were no statistically significant differences in terms of atrophy, hyperplasia and endometrial cancer between the groups $(\mathrm{p}=0.786)$.

\section{Discussion}

In the present randomized controlled study, we aimed to evaluate the impact of vaginal misoprostol and a rectal NSAID on pain relief during Pipelle endometrial biop- 
Table 1. Patient characteristics and pain scores in each group

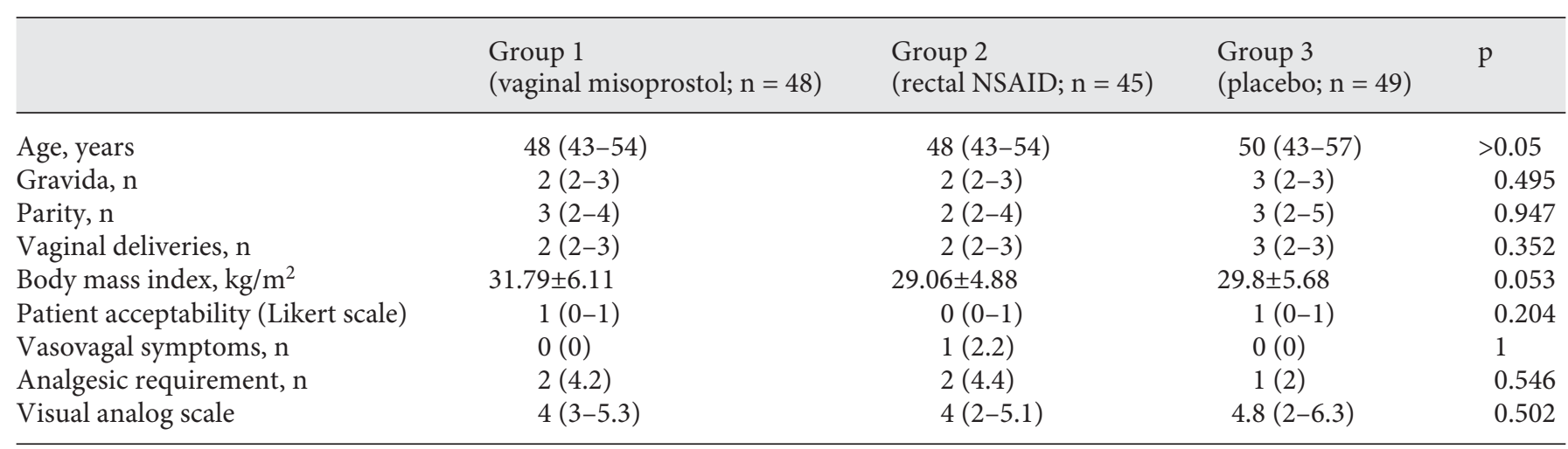

Normally distributed data are presented as mean \pm SD; nonnormally distributed variables are median values, and values in parentheses are either the range $(25-75 \%)$ or percentage. A p value $<0.05$ was considered statistically significant.

sies. We determined that vaginal misoprostol and the rectal NSAID had similar effects on pain perception during Pipelle endometrial biopsies when compared with the placebo.

The major strengths of our study are that the patients and surgeons were blinded, the sample size was appropriately powered, and the control group received a placebo. We randomized the groups blindly to obtain homogeneous study groups. The undesired psychological limitations were prevented with placebo use. However, our study still has some limitations. For example, we did not evaluate the educational status of the patients, which may affect the ability to identify perceived pain on the visual analog scale. The other limitation of the study is that the medication was self-administered. Improper drug-insertion could affect the subsequent pain reduction. Because the randomization was blinded, we were not able to assign the patients equally according to their menopausal and gravida status. Therefore, we compared the menopausal status and gravida of the patients and found that there were no statistically significant differences among the groups.

Although Pipelle endometrial biopsy is one of the most common procedures performed without anesthesia in outpatient clinics, patients may suffer from mild to severe pain. Traction of the cervix with the tenaculum, insertion of a Pipelle through the cervix and the biopsy itself are all potential causes of pain [11]. Medications blocking or reducing the nerve impulses during any part of the procedure may result in pain relief.

Perrone et al. [16], who evaluated patients receiving $400 \mu \mathrm{g}$ of oral misoprostol $3 \mathrm{~h}$ before endometrial biop- sies, could not demonstrate a reduction in cervical resistance or pain intensity. They also reported that oral misoprostol caused more uterine cramping and pain. Bunnasathiansri et al. [17] assessed the efficacy of $400 \mu \mathrm{g}$ of vaginal misoprostol $6 \mathrm{~h}$ prior to dilation and curettage in postmenopausal women, and they reported that the medication was unable to reduce cervical resistance or to dilate the cervix. Temel et al. [18] suggested that genital atrophy and decreased blood flow may reduce the absorption of vaginal misoprostol in postmenopausal women. They also reported that oral or sublingual misoprostol is the best strategy for ripening the cervix prior to fractional curettage in postmenopausal women. Oral administration was also supported by Ghosh and Chaudhuri [15] after they compared the effect of $400 \mu \mathrm{g}$ of oral misoprostol $12 \mathrm{~h}$ prior to dilation and curettage, and were able to demonstrate that oral misoprostol is able to prime the cervix only in postmenopausal women. In contrast to the study by Perrone et al. [16], the other studies $[15,18]$ were designed for the medication to be administered $12 \mathrm{~h}$, rather than $3 \mathrm{~h}$, prior to the procedure. In our study, $34 \%$ of the subjects in the misoprostol group were postmenopausal women; therefore, vaginal malabsorption may be the cause of the low misoprostol efficacy.

The pain-relieving effect of NSAIDs was previously evaluated in a daily gynecology practice. Poomtavorn and Phupong [22] administered $50 \mathrm{mg}$ of rofecoxib, an NSAID, 60 min prior to uterine curettage under a paracervical bloc and were not able to demonstrate a significant pain reduction during the procedure. They also suggested that prostaglandins are not the main source of pain during the procedure. However, Phittayawechwiwat et al. 
[23] and Manyou and Phupong [24] administered 90 and $120 \mathrm{mg}$ of the NSAID etoricoxib to women undergoing fractional curettage under a paracervical bloc, and in both studies they found a small difference in pain perception compared to placebo. Siddle et al. [25] administered 550 $\mathrm{mg}$ of oral naproxen sodium $1 \mathrm{~h}$ prior to Vabra suction curettage and did not identify any pain relief. Dogan et al. [7] also demonstrated that $550 \mathrm{mg}$ of naproxen sodium $1 \mathrm{~h}$ prior to a Pipelle endometrial biopsy did not have a beneficial effect on pain. However, the combination of intrauterine anesthesia and naproxen sodium has been shown to have a promising effect on pain reduction. In addition to the study by Poomtavorn and Phupong [22], this study also reveals that there are different sources of uterine pain. We used a different type of NSAID administered rectally and were also unable to demonstrate a pain-reducing effect. Further studies with different dosages, timing and combinations are necessary.

In conclusion, our study did not demonstrate a reduction in pain relief during Pipelle endometrial biopsies for patients receiving vaginal misoprostol or a rectal NSAID when compared to patients receiving placebo treatment.

\section{References}

1 Chambers JT, Chambers SK: Endometrial sampling: When? Where? Why? With what? Clin Obstet Gynecol 1992;35:28-39.

- 2 Corbacioglu Esmer A, Akbayir O, Goksedef BP, Gunduz N, Kisacık S, Dagdeviren H, Guraslan B, Ark C: Is there an appropriate cutoff age for sampling the endometrium in premenopausal bleeding? Gynecol Obstet Invest 2014;77:40-44.

-3 Kazandi M, Okmen F, Ergenoglu AM, Yeniel AO, Zeybek B, Zekioglu O, Ozdemir N: Comparison of the success of histopathological diagnosis with dilatation-curettage and Pipelle endometrial sampling. J Obstet Gynaecol 2012;32:790-794.

-4 Demirkiran F, Yavuz E, Erenel H, Bese T, Arvas $\mathrm{M}$, Sanioglu C: Which is the best technique for endometrial sampling? Aspiration (Pipelle) versus dilatation and curettage (D\&C). Arch Gynecol Obstet 2012;286:12771282.

$\checkmark 5$ Trolice MP, Fishburne C Jr, McGrady S: Anesthetic efficacy of intrauterine lidocaine for endometrial biopsy: a randomized doublemasked trial. Obstet Gynecol 2000;95:345347.

6 Hui SK, Lee L, Ong C, Yu V, Ho LC: Intrauterine lignocaine as an anaesthetic during endometrial sampling: a randomised double-blind controlled trial. BJOG 2006;113:53-57.

7 Dogan E, Celiloglu M, Sarihan E, Demir A: Anesthetic effect of intrauterine lidocaine plus naproxen sodium in endometrial biopsy. Obstet Gynecol 2004;103:347-351.

>8 Einarsson JI, Henao G, Young AE: Topical analgesia for endometrial biopsy: a randomized controlled trial. Obstet Gynecol 2005; 106:128-130.

\9 Güney M, Oral B, Mungan T: Intrauterine lidocaine plus buccal misoprostol in the endometrial biopsy. Int J Gynaecol Obstet 2007;97: 125-128.
0 Yilmazer M, Kose S, Arioz DT, Koken G, Ozbulut O: Efficacy of transcutaneous electrical nerve stimulation for pain relief in women undergoing office endometrial biopsy. Arch Gynecol Obstet 2012;285:1059-1064.

\11 Köşüş N, Köşüş A, Güler A, Simavli SA, Turhan NO: Transcervical intrauterine levobupivacaine infusion or paracervical block for pain control during endometrial biopsy. Exp Ther Med 2012;3:683-688.

12 Tang J, Kapp N, Dragoman M, de Souza JP: WHO recommendations for misoprostol use for obstetric and gynecologic indications. Int J Gynaecol Obstet 2013;121:186-189.

13 Sordia-Hernández LH, Rosales-Tristan E, Vazquez-Mendez J, Merino M, Iglesias JL, Garza-Leal JG, Morales A: Effectiveness of misoprostol for office hysteroscopy without anesthesia in infertile patients. Fertil Steril 2011;95:759-761.

14 Son GH, Kim JH, Kwon JY, Kim YH, Park YW: Risk factors for cesarean delivery after induction of labor in nulliparous women with an unfavorable cervix at or beyond 41 weeks of gestation. Gynecol Obstet Invest 2013;76: 254-259.

15 Ghosh A, Chaudhuri P: Misoprostol for cervical ripening prior to gynecological transcervical procedures. Arch Gynecol Obstet 2013; 287:967-973.

16 Perrone JF, Caldito G, Mailhes JB, Tucker AN, Ford WR, London SN: Oral misoprostol before office endometrial biopsy. Obstet Gynecol 2002;99:439-444.

17 Bunnasathiansri S, Herabutya Y, O-Prasertsawat P: Vaginal misoprostol for cervical priming before dilatation and curettage in postmenopausal women: a randomized controlled trial. J Obstet Gynaecol Res 2004;30: 221-225.
18 Temel M, Goynumer FG, Wetherilt L, Durukan B: Which route of misoprostol application is more advantageous prior to fractional curettage in postmenopausal patients? Arch Gynecol Obstet 2009;279:637-642.

19 Kauppila A, Puolakka J, Ylikorkala O: The relief of primary dysmenorrhea by ketoprofen and indomethacin. Prostaglandins 1979;18: 647-653.

20 Yildizhan R, Yildizhan B, Sahin S, Suer N: Comparison of the efficacy of diclofenac and indomethacin suppositories in treating perineal pain after episiotomy or laceration: a prospective, randomized, double-blind clinical trial. Arch Gynecol Obstet 2009;280:735-738.

21 Khazin V, Weitzman S, Rozenzvit-Podles E, Ezri T, Debby A, Golan A, Evron S: Postoperative analgesia with tramadol and indomethacin for diagnostic curettage and early termination of pregnancy. Int J Obstet Anesth 2011;20:236-239.

22 Poomtavorn Y, Phupong V: Prospective randomized, double-blinded, placebo-controlled trial of preoperative rofecoxib for pain relief in uterine curettage. Arch Gynecol Obstet 2005;273:115-118.

23 Phittayawechwiwat W, Thanantaseth C, Ayudhya NI, O-Prasertsawat P, Kongprasert $\mathrm{J}$ : Oral etoricoxib for pain relief during fractional curettage: a randomized controlled trial. J Med Assoc Thai 2007;90:1053-1057.

24 Manyou B, Phupong V: Prospective randomized, double-blinded, placebo-controlled trial of preoperative etoricoxib for pain relief in uterine fractional curettage under paracervical block. Eur J Obstet Gynecol Reprod Biol 2008;140:90-94.

25 Siddle NC, Young O, Sledmere CM, Reading AE, Whitehead MI: A controlled trial of naproxen sodium for relief of pain associated with Vabra suction curettage. Br J Obstet Gynaecol 1983;90:864-869. 